\title{
ESTRANGEIRIDADE E BUSCA DE IDENTIDADE EM PERSÉPOLIS ${ }^{1}$
}

\section{FOREIGNNESS AND SEARCH FOR IDENTITY IN PERSEPOLIS}

\author{
Mylena Fernanda Ribeiro"
}

Resumo: A elaboração deste texto veio da necessidade em depurar a experiência da personagem principal de Persépolis com a estrangeiridade. Apresentando excertos da HQjuntamente com teóricos, procura-se perceber como esta personagem iraniana é vista pelos grupos majoritariamente ocidentais ao seu redor, e como se dá a recepção destes olhares e pensamentos dirigidos a ela. Analisando o quadrinho, vemos que as pessoas ao redor de Satrapi, tratam-na como "o outro", não familiar e estrangeiro. Alguns personagens encontrados por Marji ao longo do quadrinho reproduzem essa visão que busca manter o Oriente como algo a ser constantemente silenciado. Ao se defrontar com tal realidade, a protagonista vê a necessidade de reafirmar sua identidade. Na tentativa de se afirmar francesa, em Viena, sente que deixa seu povo e sua história para trás, este é o momento que Marjane percebe a necessidade de retomar sua identidade iraniana.

Palavras-chave: Estrangeiridade; Identidade; Persépolis.

AвSтRACT: The elaboration of this text came from the need to understand the experience of the main character of Persepolis with foreignness. By presenting excerpts from the comic book together with theories, we seek to understand how this Iranian character is seen by the mainly western groups around her, and how she receives these looks and thoughts directed at her. Analyzing the comic, we see that the people around Satrapi, treat her as "the other", unfamiliar and foreign. Some characters found by Marji throughout the comic reproduce this vision that seeks to keep the East as something to be constantly silenced. When faced with such a reality, the protagonist sees the need to reaffirm her identity. In an attempt to affirm herself as French, in Vienna, she feels that she leaves her people and her history behind This is the moment that Marjane realizes the need to retake her Iranian identity.

KEY words: Foreignness; Identity; Persepolis.

\footnotetext{
${ }^{1}$ Este trabalho foi apresentado no evento X Ciclo de Estudos da Linguagem e III Congresso Internacional de Estudos da Linguagem - CIEL 2019, na Universidade Estadual de Ponta Grossa.

"Mestranda no programa de Pós-graduação em Letras pela Universidade Estadual de Londrina, atuando nos temas: estrangeiridade e busca de identidade. Email: hey-myh@hotmail.com
} 


\section{A CRIAÇÃO DOS OUTROS}

Satrapi narra em um texto intitulado "How can one be persian" uma breve história que vivenciou quando criança. Uma colega de sua turma levou-a para fora da sala alegando mostrar "algo que ela nunca havia visto antes". (SATRAPI, 2006, p. 20, tradução nossa). Marjane é dirigida até o frio de fora e diz não ver nada de novo, nem de espantante, e a menina entusiasmada mostra a neve: "você já viu neve?". (SATRAPI, 2006, p. 21, tradução nossa). Ela explica para sua colega que na verdade existe neve no Irã.

Ao nos depararmos com um relato assim, é bem provável que estejamos no mesmo lugar que a colega de classe da Marjane, achando coisas inóspitas sobre o Oriente ou sobre qualquer ser que a nós seja estrangeiro. Por vezes, recorremos ao erro de pressupor como verdades aquilo que nos foi ensinado, principalmente se formos ocidentais, sobre o oriente.

Ao nos debatermos com o que está escrito na epígrafe do livro de Said (2003, p. 07): "Não podem representar a si mesmos: devem ser representados" (Apud MARX, 1852) podemos começar a refletir melhor sobre o assunto. De fato, o orientalismo é entendido como o retrato do oriente através dos olhos ocidentais e a frase de Marx introduz bem o intuito do livro. Orienta-nos a pensar como foi essa busca (e arriscaria dizer, bem sucedida) do homem ocidental de exercer seu poder novamente sobre os estranhos a ele:

O Oriente foi constituído e depois introduzido na Europa, o orientalismo constituía um movimento científico cujo análogo no mundo da política era a acumulação e a aquisição colonial do Oriente pela Europa. Portanto, o Oriente não era um interlocutor da Europa, mas seu Outro silencioso". (SAID, 2003, p. 65).

Nas palavras colocadas por Said, tem-se a percepção de que Oriente foi usado pela Europa para benefícios somente dela própria. Sem consideração ao Oriente, nem a busca por tentar entender estes outros que a eles só serviam para exploração. Além da busca desenfreada pelo petróleo, guerras e desapropriação, o poder foi mostrado através deste silenciamento que parece ser uma característica do próprio Orientalismo, justamente por partir de um princípio que existe um "nós" (Ocidente) e existem "eles" (Oriente) que não compartilham os "nossos valores" (SAID, 2007, p. 16), e são indevidamente usados para justificar a depreciação da imagem e da cultura do outro oriental.

A definição do Orientalismo abordada por Said em seu livro a qual mais se aproxima do que buscamos tratar aqui é a do Orientalismo como forma de dominação. Esta dominação claramente do Ocidente para com o Oriente. Nas palavras do autor, explica-se:

Tomando o final do século XVIII como ponto de partida aproximado, o Orientalismo pode ser discutido e analisado como a instituição autorizada a lidar com o Oriente - fazendo e corroborando afirmações a 
seu respeito, descrevendo-o, ensinando-o, colonizando-o, governando-o: em suma, o Orientalismo como um estilo ocidental para dominar, reestruturar e ter autoridade sobre o Oriente. (SAID, 2007, p. 29)

Essa corrente de pensamento e essa forma de dominar o Oriente apresentada através do estudo do Orientalismo pode ser responsável por parte do imaginário que se criou e se disseminou dentro da cultura popular a respeito desse outro estrangeiro ser uma figura negativa. Tal imaginário é possível de ser percebido em Persépolis e o intuito aqui com este trabalho é realmente investigar se estas relações de poder, do Ocidente para com o Oriente acontecem no quadrinho e de que forma elas se dão. Por vezes isso é apresentado nas sutilezas de expressões e formas de tratar um estrangeiro iraniano e que acaba mostrando o ódio conservado dentro do cultura ocidental; outras vezes é nas ilustrações precisas de guerras e busca incessável por petróleo e riquezas.

Por fim, este texto é fruto do que se vem pesquisando sobre Persépolis para a escrita da dissertação. Dessa forma dita, apresentamos aqui o que já foi reunido e que ainda será mais explorado ao longo da pesquisa sobre a temática. O objetivo deste trabalho, além de discorrer sobre o que caracteriza e faz de Persépolis uma HQ única, é também explorar o que apresentamos com brevidade nos parágrafos anteriores, que dizem respeito ao Orientalismo e relação deste com o estrangeiro.

Procura-se mostrar que marcas são deixadas nos seres humanos provindas desse confronto étnico. Por isso abordaremos também alguns aspectos sobre a estrangeiridade e o exílio, usando algumas definições já pontuadas pela literatura sobre o tema. Buscamos pesquisar como isso tem aparecido na graphic novel analisada por nós.

Por se trabalhar com um quadrinho e ele ser constituído de texto e imagem, seria negligente da nossa parte deixar de fora as imagens. Além disso, tem-se buscado deixar que a própria protagonista conte sua história, justamente por ser sua a voz e não de qualquer outro ocidental. Diante disso é que se busca destacar marcas de estrangeiridade dentro da obra e como se deu a necessidade de buscar uma identidade que comportasse um pouco da subjetividade da protagonista. Ao se contextualizar rapidamente o quadrinho, abre-se a oportunidade de visualizar o quão amplo e complexo é este universo que Marji, a protagonista, vivenciou.

\section{RÁPIDA CONTEXTUALIZAÇÃo}

Persépolis é um quadrinho escrito por uma mulher iraniana, Marjane Satrapi. Marji é quem narra a história, a qual é marcada pela saída de seu país, deixando sua família para morar em Viena quando ainda entrava na adolescência. Desde o começo da narrativa até o final dela podemos ir acompanhando as mudanças, confusões, guerras internas e externas da personagem, e entender os eventos que circundam sua vida através de seu olhar. 
No início do quadrinho, temos uma Marji muito mais apegada à religião do que se perceberá com o passar dos anos e das páginas da HQ. Justamente por ter "nascido com a religião" (SATRAPI, 2007) ${ }^{2}$ como ela mesmo afirma, Marji trava muitos diálogos com a figura divina a qual denomina "Deus" e que por vezes, acha-o parecido com Marx.

Satrapi mostra a leveza com que uma crença pode ser tratada aos olhos infantis, mas também a ira de quem pode se sentir traído por esta figura. Isto está presente neste mesmo ser que outrora se mostrou gentil e amiga de Deus, vejamos um quadrinho:
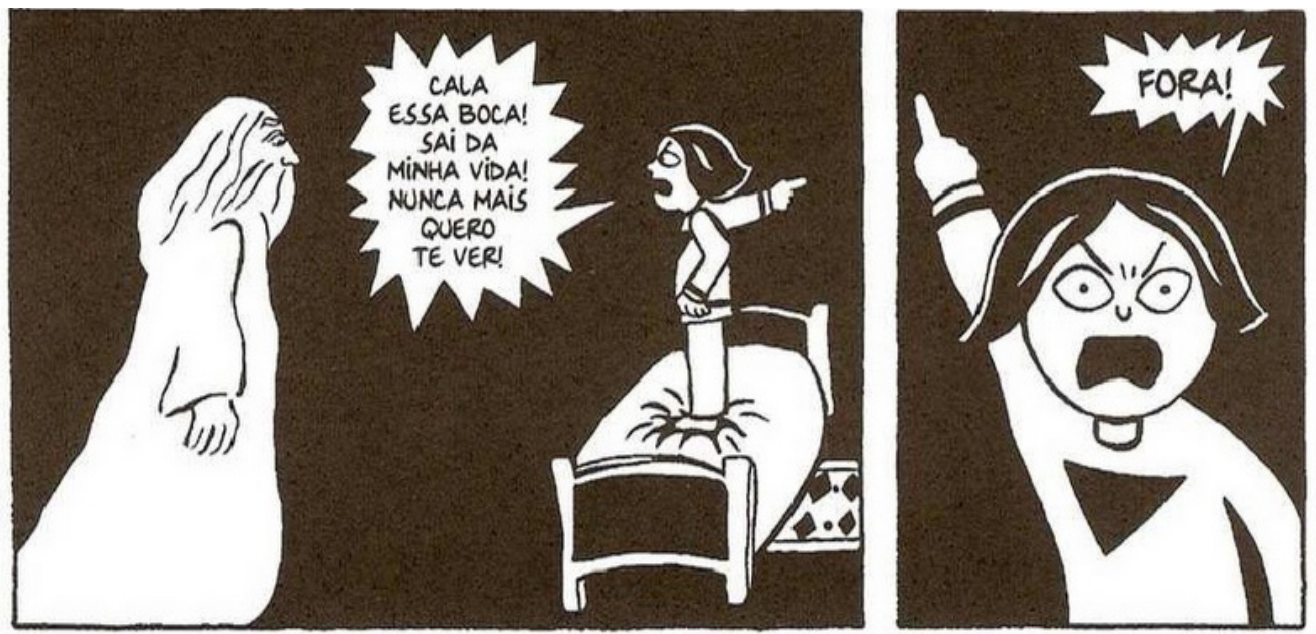

Fonte: SATRAPI, Marjane. Persépolis. Tradução: Paulo Werneck - São Paulo: Companhia das Letras, 2007.

Mas a obra é muito mais do que isso e Satrapi conta também como era a sua vida vivendo em um Irã que passou por muitas mudanças. Estas mudanças foram fortemente marcadas por decisões políticas, que também influenciaram diretamente na vida das pessoas pertencentes aquele país.

Existem cenas apresentadas fortemente marcadas pela religião e, consequentemente, marcadas pelo governo que regia o país. Um governo fundamentalista, que a partir do ano de 1980, instituiu mudanças pontuais no Irã, dentre elas a instituição do uso obrigatório do véu, mostrado pela personagem no começo da narrativa. Tudo aquilo que poderia lembrar o Ocidente e a modernização advinda deste era banido, como forma de voltar-se ao Corão e formar um governo "verdadeiramente islâmico":

\footnotetext{
${ }^{2}$ Por Persépolis não conter marcação numérica de páginas, resolvemos manter como está no original. Dessa forma, as marcações numéricas precisas não aparecerão ao longo do texto, apenas a referência simples à obra.
} 

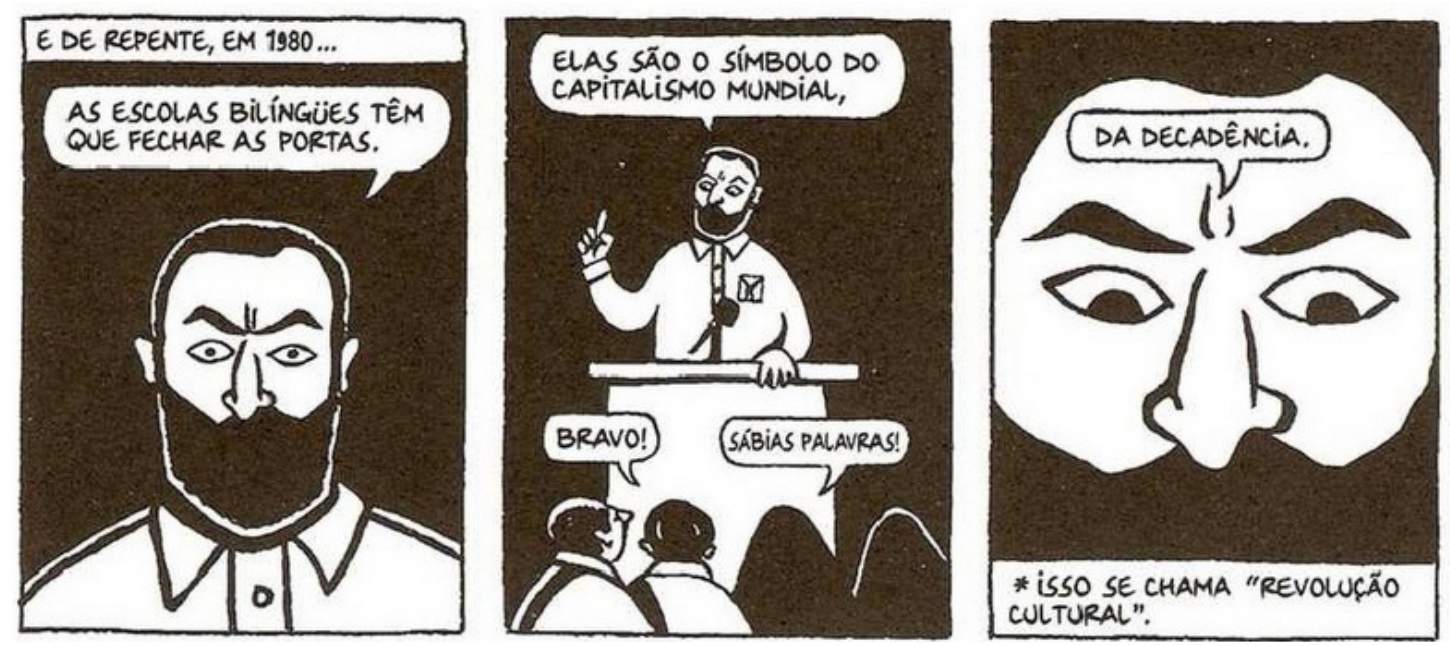

Fonte: SATRAPI, Marjane. Persépolis. Tradução: Paulo Werneck - São Paulo: Companhia das Letras, 2007.

Tudo o que poderia ser símbolo da modernização Ocidental, era banido, tais como vestimentas, maquiagens, músicas etc. Aquilo que lembrava o Ocidente lembrava a "decadência" (MAHDI, 2003. p. 07), por isso deveria ser rejeitado. Outrora, no governo do antigo Xá, as alianças que foram feitas com os EUA representaram também essa tentativa de Ocidentalização, algo que Khomeini, quis destruir (MAHDI, 2003. p. 04).

Substituído, então, por Khomeini, o Xá foi forçado a se retirar do país. Khomeini foi apoiado pelos fundamentalistas que logo mudaram todo o governo com o intuito de retornar aos preceitos religiosos e culturais do passado. O governo dele, que durou até a sua morte, em 1989, teve a constituição mudada com base no Corão e a maioria dos governantes que faziam a interpretação do livro eram homens e acabaram não dando aberturas para melhorar a condição da mulher.

É interessante refletir que colocar em prática essas leis (intuito do governo de Khomeini) queria dizer não somente ao fechamento à ocidentalização, mas grande parte dessas mudanças recaía sobre a figura feminina, sobre a mulher iraniana. Isso advém, obviamente, de uma cultura de muito tempo que mitifica o corpo e a beleza da mulher, vendo-as ora como benéfica, ora maléfica.

Estas são algumas especificidades da graphic novel que se mostraram importantes de serem destacadas, com o intuito de melhor entender a personagem e a ambientação da história.

\section{ESTRANGEIRIDADE E EXÍLIO}

A estrangeiridade e o exílio são temas de natureza física, presencial, mas também possuem sua natureza existencial. Por isso mesmo, mostram-se complexos para o ser humano 
explicar, devido ao fato de que ao se experienciar marcas muito profundas, estas podem ser deixadas, e possivelmente jamais serão apagadas.

São também temas que se aproximam e até dialogam de forma semelhante, por envolverem certa desterritorialização de um dado ser no mundo. Tanto a estrangeiridade sentida de forma empírica por um ser que não se sente participante de um dado contexto, de um dado território, ou não compartilha de um sentimento de pertencimento a um dado grupo; quanto um ser forçado a sair de seu país de origem, encontrando-se em outro território, outra cultura, sentindo-se estranho ali.

Kristeva (1994) tem notas interessantes sobre o que entende ser o estrangeiro e que reafirmam o que se vem pensando sobre o tema. A autora pontua que o estrangeiro é o que não pertence ao grupo, é o "outro" e continua dizendo:

Se voltarmos no tempo e nas estruturas sociais, o estrangeiro é o outro da família, do clã, da tribo. Inicialmente, ele se confunde com o inimigo. Exterior à minha religião também, ele poder ser o infiel, o herético. Não tendo prestado fidelidade ao meu senhor, ele é nativo de uma outra terra, estranho ao reino e ao império (KRISTEVA, 1994, p. 101).

De fato, então, vê-se esta separação que foi criada o que "nós" somos, e o que "eles" ou os "outros" são. Estas separações criadas têm suas bases fundadas na ideia que se criou do outro e que a partir disso, foi disseminada ao longo dos séculos. Said alerta sobre isso também:

E logo adiante da fronteira entre "nós" e os "outros" está o perigoso território do não-pertencer, para o qual, em tempos primitivos, as pessoas eram banidas e onde, na era moderna, imensos agregados de humanidade permanecem como refugiados e pessoas deslocadas (SAID, 2003, p.50).

Esse "não-pertencer" destacado pelo autor é bem interessante de ser pensado aqui, pois ele compartilha coisas em comum com a estrangeiridade, justamente pela sensação de não pertencer a lugar algum gerar o sentimento de estrangeiridade. No quadrinho Persépolis quando, depois de mudar de seu país (Irã) e de estudar em Viena, Marjane retorna ao Irã e apresenta ao leitor um sentimento de perda de identidade. Marji parece não saber ao certo quem é depois de todas as experiências que teve fora de seu país. No seu retorno, encara ainda na narrativa de seu pai os acontecimentos que ela perdera por estar fora; a realidade dos sofrimentos do seu povo, que parecem intensificar essa sensação de não pertencer a lugar algum. A própria personagem narra aos leitores, o momento de sua volta e o início de um momento de depressão: 


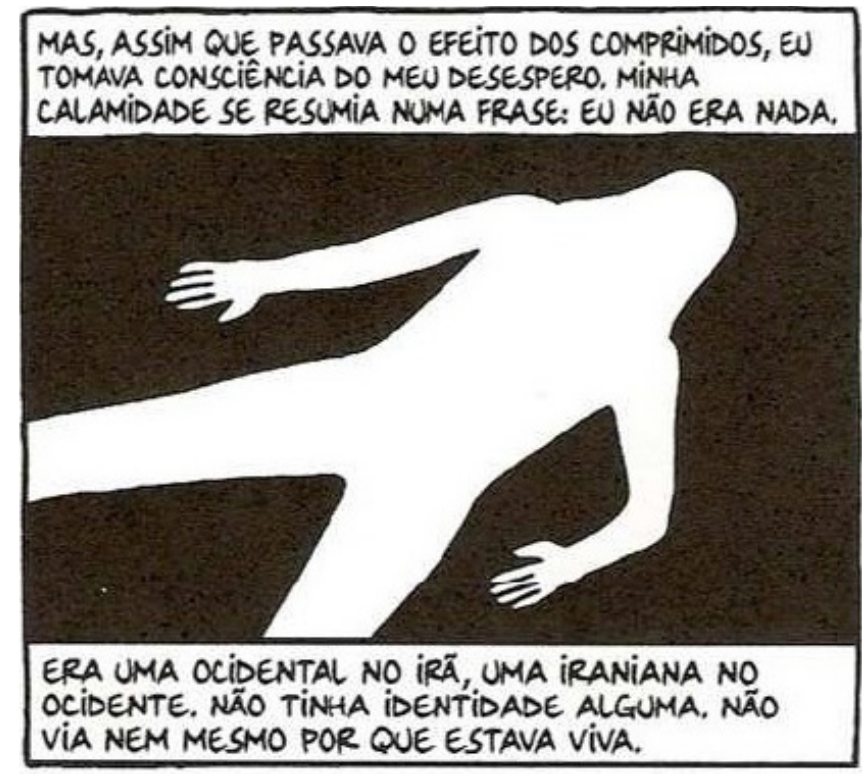

Fonte: SATRAPI, Marjane. Persépolis. Tradução: Paulo Werneck - São Paulo: Companhia das Letras, 2007.

Este talvez seja um dos momentos mais imagéticos na narrativa de Satrapi, daquilo que poderia representar ser uma estrangeira em seu próprio país, e também no próprio Ocidente, onde outrora habitou. Ela mostra carregar essa sensação de não pertencimento, de ficar em um meio onde não se encaixa por completo. É interessante retornar a Said e refletir sobre o que ele diz em: "Uma vez banido, o exilado leva uma vida anômala e infeliz, com o estigma de ser um forasteiro." (SAID, 2003, p. 53).

O exílio é entendido como um movimento forçado, um ser que foi forçado a sair de seu lugar de origem. Nas palavras de Said (2003), o exílio seria "uma solidão vivida fora do grupo: a privação sentida por não estar com os outros na habitação comunal". (SAID, 2003, p. 50). Neste caso, o exílio é um processo que termina na saída do ser de seu lugar "de origem", mas sabemos que este processo não termina ai. Por isso que este trabalho busca ater-se ao sujeito, em voltar o olhar deste exílio para o sujeito, para as marcas no ser experienciador.

Ainda em Said (2003), observamos um pouco disso. Já no início de Reflexões sobre o exílio, podemos começar a refletir sobre o exílio ser de natureza complexa e dolorosa para o ser que o experimenta:

O exílio nos compele estranhamente a pensar sobre ele, mas é terrível de experienciar. Ele é uma fratura incurável entre um ser humano e um lugar natal, entre o eu e seu verdadeiro lar: sua tristeza essencial jamais pode ser superada (...) As realizações do exílio são permanentemente minadas pela perda de algo deixado para trás para sempre. (SAID, 2003, p. 46). 
Tudo isto ao que indica compreende a sensação experienciada pela protagonista. Ela reafirma que nenhuma das opções listadas e vividas por ela lhe são benéficas: ser "uma Ocidental no Irã, uma iraniana no Ocidente". (SATRAPI, 2007). Em cada uma dessas vivências ela carrega a sensação de insuficiência, tanto para o Irã (pela percepção alheia de ela havia deixado o país e se "ocidentalizado"); ainda mais para o Ocidente, carregando a marca de forasteira, de estrangeira, entre tantas outras.

Este estigma da "forasteiridade" fica claro em outro momento da narrativa, em que é destratada por uma pessoa qualquer que a viu no metrô e a reconheceu estrangeira:

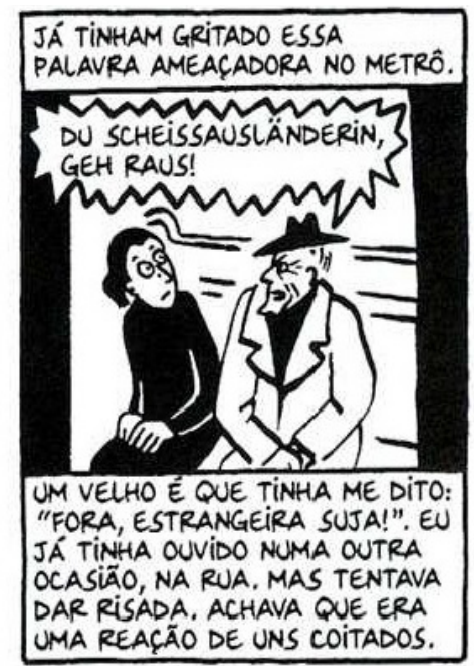

Fonte: SATRAPI, Marjane. Persépolis. Tradução: Paulo Werneck - São Paulo: Companhia das Letras, 2007.

Estrangeira. Mais uma vez esta palavra, mais uma vez uma intensificação deste sentimento que parece se internalizar a cada pessoa que passa na vida da personagem. Apesar de ser um momento eventual e a personagem não ter um vínculo com a pessoa que a destrata isso ilustra bem o racismo que envolve os seres humanos quando se diz respeito aos estrangeiros entrar no que eles acham ser "seu país". (SAID,1990. p. 27). Em crítica à obra de Pipes, Said fala algo muito interessante que se encaixa ao que estamos trabalhando:

Observe-se que não se trata de qualquer intercâmbio entre os pontos de vista do islã e os de um estrangeiro: nada de diálogo, discussão ou reconhecimento mútuo. Há uma afirmação categórica de qualidade que o dirigente ocidental ou seu fiel servidor possui graças a ser ocidental, branco e não-muçulmano. (SAID, 2003, p. 69).

Ou seja, simplesmente por não pertencer aquele grupo o qual supõe ser melhor, acredita que tem direito de determiná-lo como inferior à sua tríade: ocidental, branca e não-muçulmana. 


\section{A BUSCA DE SI}

Marjane ainda tentou se integrar. Quando adolescente mudou-se para Viena e sentiu que todas as suas tentativas foram falhas. Chegou ao ponto de negar a sua nacionalidade, alegando-se "francesa". Contudo, os seus esforços sempre se mostravam falhos, como a personagem mesma diz:

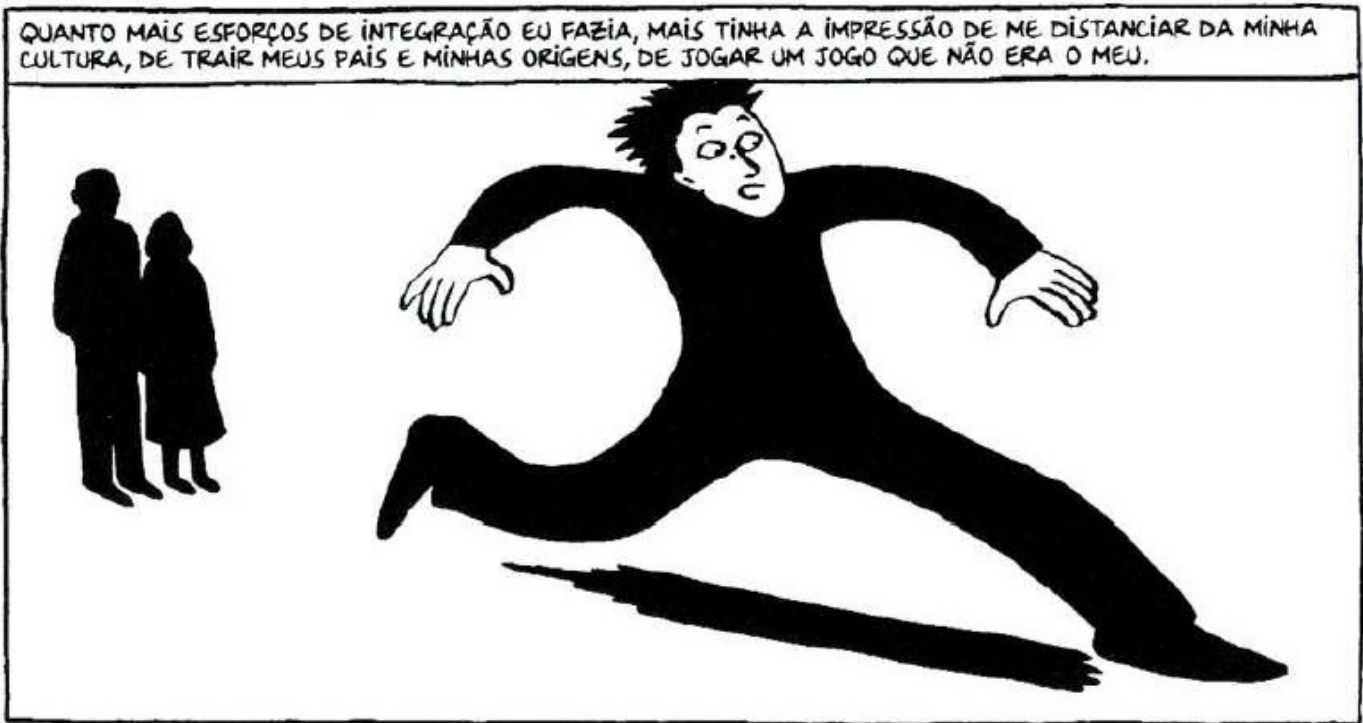

Fonte: SATRAPI, Marjane. Persépolis. Tradução: Paulo Werneck - São Paulo: Companhia das Letras, 2007.

É importante contextualizar que a personagem principal estava na adolescência quando buscava essa “integração", algo que pode parecer uma busca muito simplória e comum, mas é ainda de extrema importância pensar que ela é uma adolescente tirada do seu país de origem e colocada em uma cultura que foi moldada a pensar no oriental como "estranho", como "o outro" (SAID,1990, p. 27). Assim, somos levados a não menosprezar esses sentimentos, mas a pensar que esses inícios refletem na formação desta personagem e na sensação que se intensificou na sua vida adulta.

Estes são pontos que corroboram diretamente na formação identitária da personagem principal. Bernd (1992) pontua algumas correlações entre a busca de uma identidade e de esta estar relacionada principalmente com a relação que se tem com o outro. Com isso, tomemos este excerto:

Admitir correlações imediatas entre características raciais ou geográficas, por exemplo, e a construção de uma determinada cultura, é não apenas cientificamente falso como ideologicamente perigoso e pode levar a conclusões racistas segundo as quais somente indivíduos pertencentes à raça $\mathrm{X}$, ou habitante da região $\mathrm{Y}$, são capazes de produzir certos objetos culturais. (BERND, 1992, p. 14). 
Aqui a autora está se referindo principalmente sobre o peso da formação identitária tem para com o indivíduo e para com a sociedade. Ela fala justamente de argumentos em que pairam as suas análises em cor de pele e dados biológicos para determinar se uma pessoa é inferior a outra. É interessante como essa relação de identidade tem a ver com a relação que se tem com o outro, ou seja, com a alteridade. Beauvoir (1970, p. 10-11) já dissera que para que a mulher fosse tida como o segundo sexo, partiu-se do ponto em que existira um sexo primário que colocava este outro sexo (o feminino) como secundário e inferior a ele. Dessa mesma forma, tomamos o outro para dizer quem somos:

A literatura atua em determinados momentos históricos no sentido da união da comunidade em torno de seus mitos fundadores, de seu imaginário ou de sua ideologia, tendendo a uma homogeneização discursiva, à fabricação de uma palavra exclusiva, ou seja, aquela que pratica uma ocultação sistemática do outro, ou uma representação inventada do outro. (BERND, 1992, p. 21).

Neste momento de seu texto, a autora fala sobre como a literatura tem parte nesta visão que se criou dos negros e dos índios no Brasil. Diante desse relato, é importante refletir sobre que ideia se tem formado sobre o estrangeiro; sobre os iranianos; sobre a mulher iraniana etc.

No quadrinho, são apresentados alguns momentos em que aparecem pessoas ao redor de Marji expressando seus pensamentos a respeito dos estrangeiros. Seja na figura da mãe de seu namorado, expulsando-a de casa sem motivo que justificasse tal ato; seja na forma que a dona da pensão em que Marji está hospedada também a trata, chamando-a de "prostituta" ao levar seu namorado para o quarto da pensão. Dentre tantos momentos, tomemos um apenas para ilustrar como exemplo, o das freiras, de outro pensionato que ela ficou:
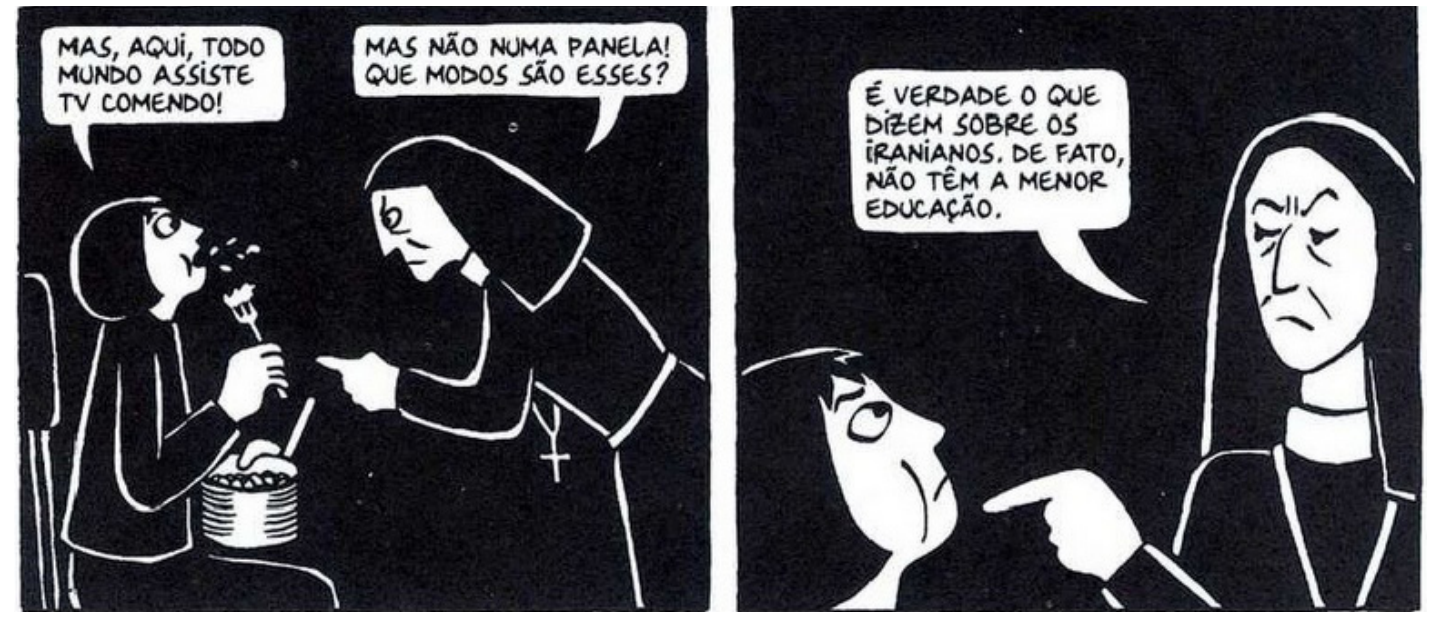

Fonte: SATRAPI, Marjane. Persépolis. Tradução: Paulo Werneck - São Paulo: Companhia das Letras, 2007. 
A narradora responde no mesmo tom do da freira e acaba tendo que encarar a expulsão do local onde estava morando. Mas o que marca é a visão errônea que a freira tem dos iranianos. Partindo de um fato banal, ela usa desse estigma que Marjane já carregava, para atacar a personagem e tentar, mostrar que os iranianos são diferentes dos ocidentais, que são menos cultos e educados, marcando novamente a diferença que pontuamos no começo deste texto, sobre "nós" e "eles". Neste excerto parece ficar bem clara a distinção que a freira faz do "nós" (Ocidente), as freiras; “eles” (Oriente), Marji. Ela usa desse artifício para mostrar que a soberanidade prevalece ocidental e que Marjane provavelmente veio de uma cultura inferior à dela.

\section{REFERÊNCIAS}

BEAUVOIR, S. de. O Segundo Sexo: Fatos e Mitos. Tradução: Sérgio Milliet. São Paulo: Difusão Européia do Livro, 1970. Ed. $4^{\mathrm{a}}$.

BERND, Z. Literatura e identidade nacional. Porto Alegre: Ed. Da Universidade/ UFRGS, 1992. MAHDI, Ali Akbar. Iranian Women: Between Islamization and Globalization. In: Iran Encountering Globalization: Problems and Prospects, Edited by Ali Mohammadi. London and New York: Routledge/Curzon, 2003.

SAID, E. Reflexões sobre o exílio. In: Reflexões sobre o exílio e outros ensaios. Tradução: Pedro Maia Soares. São Paulo: Companhia das Letras, 2003. p.46-60.

SAID, E. O Orientalismo reconsiderado. In: Reflexões sobre o exílio e outros ensaios. Tradução: Pedro Maia Soares. São Paulo: Companhia das Letras, 2003. p.61-78.

SAID, E. Orientalismo: O Oriente como Invenção do Ocidente. Tradução: Tomás Rosa Bueno. São Paulo: Companhia das Letras, 1990.

SATRAPI, M. How can one be Persian. In: AZAM ZANGANEH, L. (Ed). My Sister, Guard Your Veil; My Brother, Guard Your Eyes: Uncensored Iranian Voices. Boston: Beacon Press, 2006. SATRAPI, M. Persépolis. Tradução de Paulo Werneck. São Paulo: Companhia das Letras, 2007.

Recebido para publicação em 6 de Março de 2020. Aceito para publicação em 20 de Março de 2020. 